\title{
Preliminary Analyses of Expression of Learning and Memory Related Genes in Honey Bees (Apis mellifera) in Free-Choice Learning Paradigms
}

\author{
Timothy E. Black¹, Medhat Radi², Amanda Somers ${ }^{1}$, Charles I. Abramson ${ }^{1}$ \\ ${ }^{1}$ Laboratory of Comparative Psychology and Behavioral Biology, Psychology Department, Oklahoma State \\ University, Stillwater, USA; ${ }^{2}$ Pest Physiology Department, Plant Protection Research Institute, ARC, Giza, Egypt \\ Correspondence to: Charles I. Abramson, charles.abramson@okstate.edu \\ Keywords: Honey Bees, Learning, Memory, Gene Expression, microRNA \\ Received: May 6, $2021 \quad$ Accepted: June 4, $2021 \quad$ Published: June 7, 2021 \\ Copyright $\odot 2021$ by author(s) and Scientific Research Publishing Inc. \\ This work is licensed under the Creative Commons Attribution International License (CC BY 4.0). \\ http://creativecommons.org/licenses/by/4.0/ \\ (c) (i) Open Access
}

\section{ABSTRACT}

Honey bees are an established animal model for studying learning and memory related behaviors. In recent years, honey bees have become more common as a model for investigations of molecular biology, including gene expression. Honey bees have been used to extrapolate genetic functions found in other invertebrates, such as Drosophila melanogaster. The honey bee model has also provided a means for isolating novel genes, including non-coding microRNA fragments. Integrating the study of learning and memory with molecular genetics, the present work examines the effect of learning acquisition and memory consolidation in free-choice paradigms on the expression of a suite of genes of interest. Results suggest that short-term learning acquisition causes differential expression of microRNA fragments, while memory consolidation differentially affects the expression of the serine/threonine protein kinase gene in honey bees. These results corroborate previous findings suggesting the importance of protein kinases in the formation of long term memory, and suggest that microRNA may play a large role in regulation of cytoskeletal scaffolding proteins.

\section{INTRODUCTION}

The purpose of this work is to examine the effect of free-choice learning on a suite of genes in honey bees (Apis mellifera). The honey bee genome was sequenced nearly twenty years ago [1]. Since then, comparative analyses and bioinformatics have identified homologs and orthologues between the Apis genus and other insect models. In addition to the shared similarities between Apis and Drosophila, there are marked differences. Two of the most notable differences being honey bees' unique genes associated with caste determination and labor division and increased similarity to vertebrate genomes compared to Drosophila [2].

Before genome sequencing, the honey bee was a well-established model for behavioral measures of 
learning [3-5]. Earlier research concentrated on the physiology of learning, focusing on mushroom bodies and the structure of memory systems $[6,7]$. Now honey bees are an emerging model organism for the exploration of genetics $[1,8]$. Comprehensive research into the differential gene expression profiles between the brains of individuals from different castes (e.g., nurse bees versus foragers) has been published [9]. Aspects of learning have been shown to alter the expression of associated genes within this species [10], making them an ideal choice for examining the effects of free choice on learning and memory-based gene expression. In this current research, we add to the literature and expand our understanding of the mechanisms of honey bee learning and memory using genetic tools.

\subsection{Honey Bees as Learning Models}

Honey bees have provided a model of invertebrate learning in a wide variety of paradigms. As a model of invertebrate learning, honey bees show reliable classical conditioning of innate responses, such as the proboscis extension [11, 12] and sting extension responses [13]. Likewise, repeated studies have shown that honey bees can display learning in free-flight paradigms, such as geospatial learning tasks [14], and in modified foraging tasks [3, 14-16]. Honey bees have also been subject to a number of more restrictive choice paradigms including shuttlebox tasks $[17,18]$ and Y-maze tasks $[19,20]$. The findings from these studies, which encompass a diverse set of tasks, demonstrate that honey bees are an ideal organism to examine the behavioral outcomes of a variety of learning paradigms.

In addition to the previously mentioned tasks, honey bees have shown the ability to recall information learned in previous experimental exposures. In the short term, studies have shown that honey bees will alter their behavior based on learning acquired in previous manipulations or environments [18, 21]. In many cases, the acquisition of these behavioral changes occurs quickly, with Wainselboim et al. [21] observing foraging behavior changes following a single return visit to the foraging patch, and Black et al. [18] observing changes in avoidance behavior up to several hours after a color preference manipulation was implemented.

Like the number of learning paradigms used within the species, the duration of learning acquired in honey bees varies. Hammer and Menzel [22] noted that olfactory-based learning of the proboscis extension response is relatively short-lived, decaying after roughly 24 hours to pre-conditioning levels. Motor tasks and foraging tasks, however, appear to be more robust, with foraging studies often showing repeated visits to the same location over repeated days [23]. As such, when examining the effects of learning and memory, it is important to select behavioral outcomes representative of both acquisition and recollection.

\subsection{Genetic Expression}

In addition to their role as a behavioral model organism, honey bees are rapidly becoming a model for genetic explorations [1]. A vast majority of genetic analyses in insects are conducted in the well-known model organism Drosophila melanogaster. Studies show that honey bees show remarkable genetic similarity to Drosophila [8]. This makes honey bees a logical step for extrapolating genetic results seen in a model organism to additional species. In addition to their sequenced genome [1] and similarity to Drosophila [8], honey bees have been used as a model of gene expression in a variety of inquiries. These include the expression of learning-based genes [10], physiological stress [10, 24, 25], and foraging tasks [26].

Four genes were selected for their functions related to learning and memory formation in honey bees and related insects. These genes of interest include coding genes, which produce mRNA for protein translation, and genes that produce non-coding microRNA. The genes consist of the actin-related protein 1 (ARP1), the Serine/Threonine Protein Kinase (S/T), and the microRNA fragments 210 and 932 (mir210; 932). While many of these genes have been linked to functions of neural plasticity or synaptic transmission, few have been examined in terms of expression following behavioral performance within honey bees. As such, this work presents a preliminary analysis of gene expression based on learning performance.

\subsubsection{Protein Coding Genes}

The actin gene and actin-related proteins (ARPs) originated from a shared common ancestor [27, 28]. 
ARPs are known to be conserved as highly as histone during the evolution of eukaryotes [29]. ARPs are present in all eukaryotes as well as numerous species of bacteria and archaea [30]. Actin is involved in filament formation in the cytoskeleton, but also plays an important role in many cellular functions and biochemical activities ranging from motility and muscle contraction to cell division and signaling. Actin has been identified as a major cytoskeletal scaffold protein within honey bee brains and is linked to extensive neural plasticity systems within honey bees [31]. Actin-related proteins share modest sequence similarity to actin isoforms and are characterized by their degree of similarity to actin. The ARP family comprises ten members, of which, ARP1 is the most similar to actin [32].

Cristino et al. [33] documented a change in the expression of the ARP1 gene corresponded to molecular changes in the brain of honey bees during memory formation in an associative olfactory learning paradigm. Based on this finding, ARP1 expression has functions that potentially affect learning and memory and activity-dependent neuronal plasticity in honey bees. This is not surprising, as the actin cytoskeleton has been identified as a key mediator in receptor activation during learning and cellular changes in long-term memory in the amygdala [34].

Serine/threonine protein kinase $(\mathrm{S} / \mathrm{T})$ was the second gene of interest in the current investigation. Many protein kinases are involved in higher-order functions of the central nervous system, including synaptic plasticity, which is required for learning and memory performance [35, 36]. Tejedor et al. [37] indicated that protein kinases play critical roles in growth, differentiation, and brain development and function. Protein kinases related to learning and memory affect synaptic transmission or ion channel density, often regulating gene expression and protein synthesis, which can stimulate neurogenesis [38].

A novel serine/threonine protein kinase was isolated in mice [39]. Expression thereof was shown to transiently increase during the consolidation of Pavlovian fear memory [40]. S/T is also reportedly involved in memory formation in Drosophila, where S/T and the cAMP-dependent protein kinase A boost long-term memory (LTM) involved in the maintenance of anesthesia-sensitive memory (ASM), which includes short-term memory (STM) and middle-term memory (MTM) [41].

\subsubsection{MicroRNA}

MicroRNA (miRNA) are classified as short non-coding or non-messenger RNAs [42]. The role of miRNAs has become an area of major interest in the regulation of phenotypic and developmental plasticity. These miRNA are known to be modifiers in learning and memory processes in both vertebrates and invertebrates [43-46]. Preliminary studies on the spatiotemporal patterning of miRNA expression in adult honey bees suggested that the miRNA landscape changes during the age-dependent switch in labor division from nurse to forager in female workers [31, 47-52].

The miR-210 gene was selected based upon prior implication in learning and memory in honey bees. It was previously reported that honey bees' miR-210 was differentially expressed when performing different behavioral duties (e.g., brood care and foraging) [47] A contribution of miR-210 to impair the cognition of rats was detected by Ren et al. [53] in addition to Cristino et al. [33] predicting the presence of eight mRNA targets for miR-210 in honey bees.

MiR-932 to date has only been isolated in insects such as honey bees [54] and Drosophila [55]. It was shown that miR-932 regulates Act5C in laboratory fruit flies and honey bees, therefore miR-932 has a direct effect on the actin-related plasticity mechanism [56, 57]. Cristino et al. [33] reported that high expression of miRNAs, including miR-932, in honey bees aids to boost the stability of memory by managing the dynamics of actin polymerization. In this regard, the decreased levels of miR-932 have a significant effect on olfactory LTM recall but not memory acquisition.

\subsection{The Present Work}

Given the varied nature of the learning ability and memory duration of honey bees and the known impacts of the genes of interest, the present work undertook two experiments. Both experiments were conducted to explore how learning acquisition and memory formation affects the expression of the genes of interest. Experiment 1 made use of a Y-Maze choice paradigm to assess changes in short-term learning 
acquisition. Experiment 2 made use of a repeated exposure flying foraging task to assess memory formation. It was expected that the gene expression of the four genes of interest would differ between individuals displaying high performance on the learning tasks, and those that displayed poor learning.

\section{METHODS}

\subsection{Subjects}

Subjects consisted of honey bees (Apis mellifera) from research hives maintained by the laboratory of Comparative Psychology and behavioral Biology at Oklahoma State University (Stillwater campus) near Stillwater, OK. All subjects were trained to a feeder containing a $1.5 \mathrm{M}$ sucrose solution located roughly 20 $\mathrm{m}$ away from the hives. Upon landing on the feeder, bees were collected individually in $15 \mathrm{~mL}$ falcon tubes. Collection of subjects in this manner was conducted, so that all subjects could safely be assumed to be foragers, and as such in the same and latest stage of the honey bee life cycle [58].

For Experiment 1 , subjects $(n=56)$ were transported to a research laboratory and placed in a communal wire mesh cage with a mixture of honey and sucrose as a food source. Experimental protocols were conducted within 24 hours of the subjects' capture.

In Experiment 2, subjects $(\mathrm{n}=52)$ were captured using the same method and marked using Testors ${ }^{\mathrm{TM}}$ enamel paints for identification. Marks were placed on either the abdomen or thorax of the individuals to avoid impeding locomotion once dried. Subjects were housed in a wire mesh cage with no access to food prior to experimental protocols, and were subject to experimentation within 1 hour of their capture. Upon completion, the subjects were placed back into the same cage with access to a sucrose and honey mixture as a food source.

\subsection{Experiment 1}

Experiment 1 made use of a Y-maze choice learning paradigm. In invertebrate systems, Y-mazes are frequently used to assess both spatial learning, and learning following classical conditioning $[19,59]$. This method was selected to examine learning in the short-term. This methodology allowed subjects free mobility and individual choice; whereas other measures of classical conditioning, like the proboscis extension response $[60,61]$, require restraining the individual, and may induce physiological stress-related gene expression.

\subsubsection{Apparatus}

The Y-maze apparatus consists of a three-armed maze 3D-printed using white acrylonitryle butadiene styrene (See Figure 1) [62]. Each arm has internal dimensions measuring $50 \mathrm{~mm} \times 50 \mathrm{~m} \times 100 \mathrm{~mm}$ positioned at an equidistant angle from the opposing two arms. Slots are positioned at the end of two arms to allow insertion of color stimuli, which consist of $53 \mathrm{~mm} \times 55 \mathrm{~mm} \times 2 \mathrm{~mm}$ 3D-printed acrylonitryle butadiene styrene plate painted with Testors ${ }^{\mathrm{TM}}$ blue or yellow enamel paint. The surface of the apparatus was enclosed using a sheet of $2 \mathrm{~mm}$ plexiglass to ensure subjects remained in the apparatus during testing. Placed at the bottom of each color stimulus within the Y-maze was a well containing $40 \mathrm{~mL}$ of either a $1 \mathrm{M}$ sucrose solution or a $1 \mathrm{M} \mathrm{NaCl}$ solution.

The third arm ends in a docking slot, to allow for introduction of subjects from containment chambers. Each containment chamber consists of a 3D-printed acrylonitryle butadiene styrene compartment with internal dimensions of $4 \mathrm{~cm} \times 5 \mathrm{~cm} \times 4 \mathrm{~cm}$. On the portion of the containment chamber that is slotted into the docking slot, a slot is present to allow for the opening and closing of a $45 \mathrm{~mm} \times 45 \mathrm{~mm} \times 2$ $\mathrm{mm}$ acrylonitryle butadiene styrene gate. This allows researchers to release subjects from the containment chamber into the docking arm of the Y-maze.

\subsubsection{Behavioral Protocol}

For all subjects, behavioral protocol was comprised of a training phase and a test phase. Within the training phase, there were six five-minute trials offset by five-minute rest periods. For each subject, sucrose 


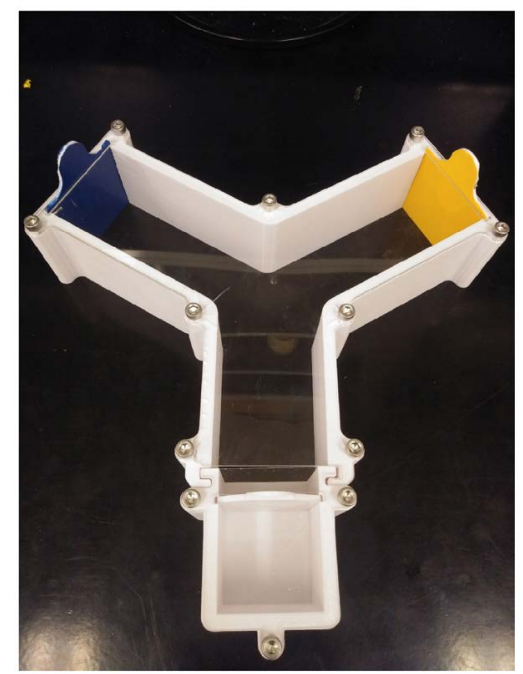

Figure 1. Y-Maze apparatus Located at the top of the apparatus are the two choice arms with visual stimuli. Located at the bottom is the containment chamber with removable gate to allow for release and recapture of the experimental subject. Internal dimensions of the apparatus measure $50 \mathrm{~mm} \times$ $50 \mathrm{~m} \times 100 \mathrm{~mm}$ within each arm.

and $\mathrm{NaCl}$ solutions are paired with one of the two stimulus colors (blue or yellow). Location of the color/solution pair was counterbalanced between trials to control for positional biases. The number of visits to correct and incorrect wells were recorded to determine overall individual performance.

Following the successful completion of the training phase, individuals were subject to the test phase. In test phase trials, solution wells were replaced with empty wells, and individuals were introduced to the apparatus as before. Individuals were then subjected to six additional five-minute trials offset by fiveminute rest periods. For these trials, the color corresponding initial choice was recorded, and the subject was removed from the apparatus for the remainder of the trial. The initial choice was defined as the first occurrence of the subject interacting with and searching the empty well. Visits to the correct (color paired with sucrose) and incorrect (color paired with $\mathrm{NaCl}$ ) wells were recorded to determine overall individual performance.

Individuals were removed from the experiment $(n=20)$ if they met any of the following conditions: failed to interact with either well in the training phase for three complete five-minute trials, failed to interact with either well in the test phase for three complete five-minute trials, or perished during experimental protocols. Following successful completion of the behavioral protocol, subjects were removed from the apparatus and placed into a $15 \mathrm{~mL}$ falcon tube. Falcon tubes were subsequently submerged in liquid nitrogen to cease metabolic activity and preserve samples for genetic analysis. Samples were stored in a $-80^{\circ} \mathrm{C}$ freezer until RNA extraction.

\subsection{Experiment 2}

Experiment 2 made use of a modified version of the artificial flower patch experiment by Wells et al. [63]. This experiment made use of repeated exposure to the same flower patch to assess memory formation following previous exposure in a contained free-flight design. This was selected in order to minimize experimenter handling, as well as allow individual free choice.

\subsubsection{Apparatus}

The flower patch used in this experiment consisted of a $1 \mathrm{~m} \times 1 \mathrm{~m} \times 2 \mathrm{~mm}$ plexiglass sheet. The sheet was backed with black paper, and included a grid of 64 colored circles (blue and yellow) each $8 \mathrm{~cm}$ in diameter, and distributed in the pattern seen in Figure 2. The flower patch was then housed in a $1 \mathrm{~m} \times 1 \mathrm{~m}$ 


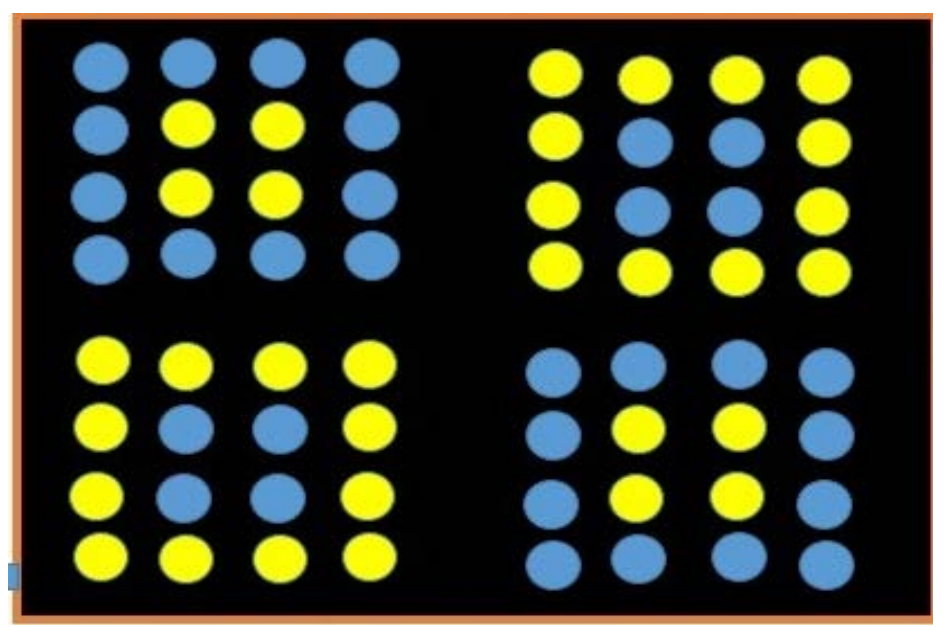

Figure 2. Diagrammatic view from above of flight arena with 64 artificial flowers arranged in four squares. The grid overall consisted of a $1 \mathrm{~m} \times 1 \mathrm{~m}$ surface, with each colored circle being $8 \mathrm{~cm}$ in diameter.

$\times 50 \mathrm{~cm}$ mesh enclosure. The flower patch enclosure was used to prevent external influences from interfering with research subjects, or external subjects interacting with the flower patch.

\subsubsection{Behavioral Protocol}

As with Experiment 1, Experiment 2 consisted of both a training phase and a trial phase. In the training phase, a well containing $40 \mathrm{~mL}$ of either a $1 \mathrm{M}$ sucrose or $1 \mathrm{M} \mathrm{NaCl}$ solution was placed at the center of each colored circle. Solutions were paired with a color stimulus, and counterbalanced between subject groups to account for any color biases. Groups of six to eight individuals were introduced to the flower patch simultaneously, and observed for a period of two hours.

Following the two-hour observation period, subjects were removed from the flower patch and placed into a communal wire mesh cage containing a sucrose/honey mixture as a food source. Subjects were housed in this manner overnight in a low-light environment at $24^{\circ} \mathrm{C}$. The following day, 24 hours past their initial introduction to the flower patch, subjects were reintroduced to the apparatus for the test phase.

Prior to reintroduction to the flower patch, empty wells were placed in the center of each colored circle. Test phases consisted of a secondary one-hour observation phase in which the number and color of well interactions were recorded for each individual. Interaction was defined by an individual searching a well or inserting its head into the well.

Individuals were removed from the experiment $(n=17)$ if they met one of the following exclusion criteria: failure to interact with a well during either training or test phases, death during training or test phases, or death during the overnight housing period. Overall, 52 individuals successfully completed the behavioral protocol.

Following successful completion of the behavioral protocol, subjects were transferred to individual 15 $\mathrm{mL}$ falcon tubes. Tubes were then submerged in liquid nitrogen to cease molecular activity and preserve samples for RNA extraction. Samples were stored at $-80^{\circ} \mathrm{C}$ until tissue and RNA extraction.

\subsection{Sample Selection}

In Experiment 1, individuals were separated into two groups (high and low performance) and a subsample of each group was selected for RNA extraction. For Experiment 1, the proportion of visits to correct wells during the test trial was used to differentiate between high-performing and low-performing individuals. As such, those with $100 \%$ correct visitation in the test trial were considered the highest per- 
forming, and those with $0 \%$ correct visitation in the test trial were considered the lowest performing. In the event of similar correct visitation, the number of overall correct visits in the training phase was used to determine subsequent ranking. 15 individuals representing high performance and 15 individuals representing low performance were selected.

A similar classification system was used for Experiment 2. The proportion of correct color visitation in the test phase determined high performing and low performing individuals. As such, individuals with $100 \%$ correct visitation were considered high-performance individuals, while those with $0 \%$ correct visitation were considered low performance. As with Experiment 1, in the event of similarly classified individuals, training phase performance was used to determine subsequent ranking. For this experiment, 10 individuals were selected to represent high performance, and another 10 to represent low performance.

\subsection{RNA Extraction and Quantification}

Following each behavioral experiment, subjects were frozen in liquid nitrogen to preserve tissue, and halt cellular processes. Subjects were removed from liquid nitrogen and stored in a freezer at $-80^{\circ} \mathrm{C}$ until dissection. Sample dissection consisted of the removal of brain tissue on a bed of solid $\mathrm{CO}_{2}$ to prevent the tissue from thawing. Dissections involved the removal of cuticle tissue from the top of the subject's head, followed by the removal of ocular and hypopharyngeal tissues. Brains were returned to the $-80^{\circ} \mathrm{C}$ freezer until RNA and DNA extraction.

Genetic material was collected from samples using a GenElute FFPE RNA/DNA purification kit (Sigma-Aldrich, St. Louis, MO), allowing the collection of both DNA and RNA. The presence of genetic material in each sample was confirmed and quantified using a NanoDrop (ND-1000, NanoDrop Technologies, Inc., Wilmington, DE, USA). RNA samples were diluted with nuclease-free water to a consistent concentration of $40 \mathrm{ng} / \mu \mathrm{L}$ to normalize analyses.

To quantify relative genetic expression, reverse transcriptase quantitative polymerase chain reaction (RT-qPCR) was conducted on the RNA samples, using a BioRad iTaq Universal qPCR kit (Bio-Rad Laboratories, Hercules, CA, USA). For each gene of interest, a master mix was created containing $300 \mu \mathrm{L}$ SYBR Green, $7.5 \mu \mathrm{L}$ reverse transcriptase, $1.8 \mu \mathrm{L}$ reconstituted forward primers, $1.8 \mu \mathrm{L}$ reconstituted reverse primers, and $288.9 \mu \mathrm{L}$ nuclease-free water. Master mixes were distributed in $8 \mu \mathrm{L}$ aliquots, with $2 \mu \mathrm{L}$ aliquots of the respective diluted sample. Each sample was replicated in triplicate for experimental control.

Samples were analyzed using a Bio-Rad CFX Connect Real-Time PCR system (Bio-Rad Laboratories, Hercules, CA, USA). Analyses consisted of a 10-minute reverse transcription phase at $50^{\circ} \mathrm{C}$, followed by a 1-minute enzymatic activation phase at $95^{\circ} \mathrm{C}$, and thirty-nine cycles of denaturation, annealing, and extension. Cycle thresholds (CT) were recorded for each sample.

\section{RESULTS}

Data for technical replicates of each sample were averaged to generate a representative cycle threshold for the organism. Data were analyzed using IBM SPSS version 24 (IBM, Armonk, NY). Comparison of each gene between high performing and poor performing subjects were conducted using independent samples t-tests with a Bonferroni correction for $\alpha$-inflation. The corrected $\alpha$-value was 0.0125 . Assumptions of Normality were assessed using a Levene's Test for equality of variance.

\subsection{Experiment 1}

The Levene's test for equality of variance was violated for the expression results of mir932 $(F=$ 10.291, $p=0.004)$. Significance was interpreted without the assumption of equivalent variance for this gene. All other genes did not violate the assumption.

No statistically significant differences were observed in cycle threshold for mir210 $(t(25)=-0.788, p$ $=0.438), \operatorname{ARP} 1(t(23)=-1.336, p=0.195)$, and $\mathrm{S} / \mathrm{T}(t(25)=-1.320, p=0.199)$. A significant difference was observed for mir932 $(t(19.016)=-2.939, p=0.008)$ with high performance individuals displaying lower cycle threshold values $(M=29.84, S D=1.26)$ than low performance individuals $(M=30.86, S D=$ 
0.049). It is important to note that cycle threshold corresponds to the number of replication cycles required to reach logarithmic RNA/DNA replication in PCR reactions. Lower cycle thresholds correspond to higher baseline RNA concentrations (See Figure 3).

\subsection{Experiment 2}

For experiment 2, the Levene's test for equality of variance was violated in the cases of both ARP1 ( $F$ $=5.071, p=0.046)$ and $\mathrm{S} / \mathrm{T}(F=4.634, p=0.047)$. As such, results were analyzed without the assumption of equal variance. Results for mir210 and mir932 did not violate this assumption.

Results for mir210 $(t(14)=-2.526, p=0.024)$, mir932 $(t(16)=-2.249, p=0.039)$, and ARP1 $(t(10.963)=0.485, p=0.637)$ showed no significant differences in cycle threshold between high performance and low performance groups. Results in the expression of S/T did display a significant difference $(t(10.228)=-3.508, p=0.005)$, with high performance individuals displaying lower cycle thresholds $(M=$ 26.07, $S D=0.08)$ than low performance individuals $(M=26.33, S D=0.21)$. These results suggest that high performance individuals had higher baseline expression of $\mathrm{S} / \mathrm{T}$ than did low performance individuals (See Figure 4).

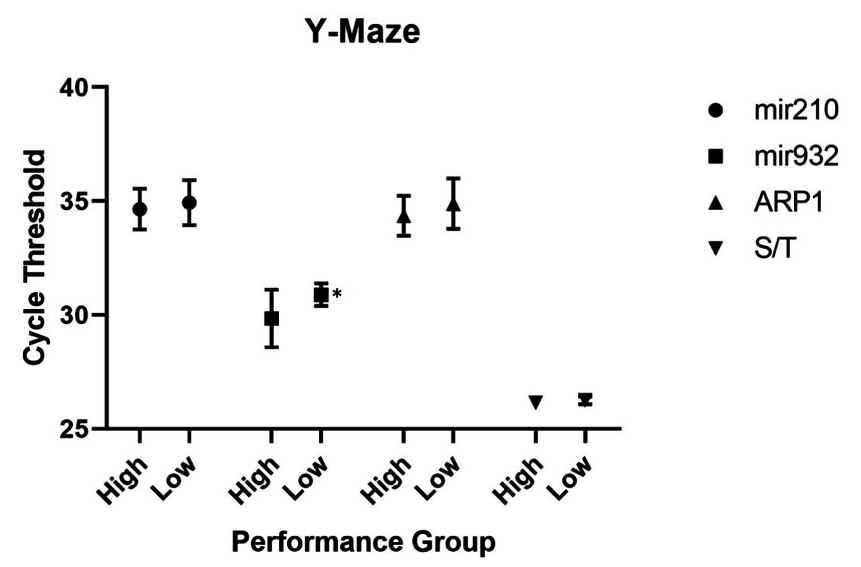

Figure 3. Gene expression by cycle threshold for all genes of interest in the Y-Maze experiment. Presented as comparison between high performance and low performance individuals. Significant differences noted with an asterisk.

Flower Patch

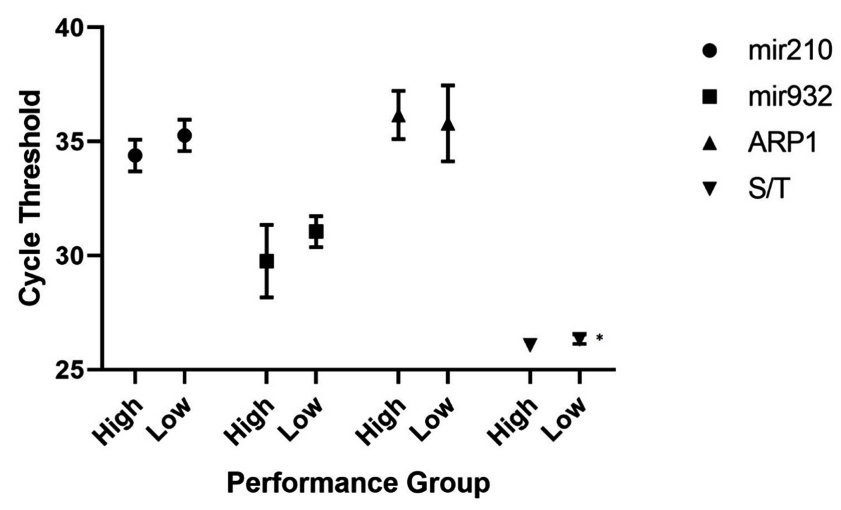

Figure 4. Gene expression by cycle threshold for all genes of interest in the flower patch experiment. Presented as comparison between high performance and low performance individuals. Significant differences denoted with an asterisk. 


\section{DISCUSSION}

The purpose of this work was to provide a preliminary assessment of whether behavioral acquisition or memory consolidation affected the expression of four genes of interest within honey bees exposed to free-choice learning paradigms. Results from the first experiment suggest that expression of mir932 appears to be affected by behavioral acquisition. The results of the second experiment suggest the expression of the S/T gene appears to be affected by memory consolidation.

Variation in the expression of mir932 in the Y-maze sample suggests that microRNA may serve as a more powerful neuromodulator in the short term than previously thought. The microRNA product of the mir932 gene has been linked to regulation of actin in honey bees [56]. Actin has been identified as a major cytoskeletal scaffold protein present in honey bee brains and is linked to systems of neural plasticity within honey bees [31]. Alterations in synaptic scaffolding as cellular systems reform following learning may result in increased expression of mir932, as systems require additional actin restructuring, suggesting that mir932 may be an adequate measure of both learning and cellular stress present in neural tissue. As such, expression of mir932 may be a result of learning acquisition promoting the restructuring of neural pathways or could potentially explain differential performance, with individuals innately expressing higher levels of mir932 displaying higher learning potential as a result of the microRNA fragment's presence. Further research is necessary to determine the directional nature of this relationship.

It is surprising then, given mir932's relationship with actin and related protein families, that significant results are not observed in the expression of ARP1. As noted by Li et al. [31] and Cristino et al. [33], actin and related proteins are necessary for the alteration of cytoskeletal scaffolding, and have been directly implicated in the onset of neuroplastic responses. The fact that we do not see a significant change in the expression of ARP1 in either experiment suggests that ARP1 in particular is likely not responsible for significant neuroplastic changes in honey bees. It should be noted that ARP1 was investigated in these studies following hypotheses by both Poch and Windsor [32] and Cristino et al. [33] and based on the structural similarity of the protein product of ARP1 and actin itself. It is possible that post-transcriptional factors, rather than mRNA transcription itself, are more influential in the role of actin and related proteins on neuroplasticity.

Additionally, it should be noted that this is the first study to link expression of a microRNA fragment directly to a behavioral intervention. Past studies, such as Cristino et al. [33] have previously only speculated about the function of microRNA fragments, complete with hypothesized mechanism. While the present study does not illustrate a clear mechanism, it does suggest that there is a difference in expression between high performance and low performance individuals of learning acquisition.

It is also possible that the expression difference observed in mir932 is linked to a behavioral phenotype, rather than a result of learning altering expression. Allelic differences in the individual may result in a preexisting difference in expression that allows for some individuals to perform better at short term learning acquisition. While the present study is insufficient to determining the causal relationship between behavior and expression, the potential for a high learning phenotype in honey bees is of great interest. Further studies are required in order to illustrate whether or not the difference in expression was a result of transcriptional or allelic differences.

The differential expression of the S/T gene in Experiment 2, in the absence of differential expression in Experiment 1, corroborates the findings of Stork et al. [40], suggesting that the gene was implicated in the consolidation of memories. This differential expression, coupled with evidence that many such protein kinases are found primarily in situations of cellular growth and differentiation [37-39], suggests that memory consolidation in honey bees is likely linked to neurogenesis or collateral sprouting in these individuals, rather than synaptic plasticity.

It is worth noting that previous inquiries in the expression of other protein kinase-related genes in honey bees have also returned null results. Black et al. [10] examined protein kinase A in an aversive conditioning choice task, and noted no significant difference between experimental groups. These results are similar to those observed in Experiment 1, as both studies made use of a short-term learning task, rather than the development of long-term learning. 
It is possible that the results seen in the present study may differ for ARP1 and S/T expression should these genes be analyzed at the protein level, rather than at the mRNA expression level. Many such proteins possess posttranscriptional effects that are also affected by the presence of behavioral phenomena that could further elevate the differences between groups. The present study made use of RNA transcription instead of protein formation in order to assess the effects of learning solely on gene expression. Results of $\mathrm{S} / \mathrm{T}$ in particular do suggest that memory consolidation, rather than learning can increase the expression of the gene. Whether or not that increase of expression corresponds to increased protein formation should be assessed by subsequent research.

Due to the results of S/T and mir932 showing differences in expression only based on one experiment each, it is possible that the type of learning is affecting expression. Experiment 2 made use of a significantly longer term manipulation, allowing for expression based off of both learning acquisition and memory consolidation. Experiment 1 on the other hand allows for exploration of strictly short term learning acquisition. The differences in these two genes of interest suggest that mir932 is affected by short term learning, while S/T is more likely affected by memory consolidation. This difference does suggest that the type of learning is potentially a factor in gene expression in this species.

The present study does present some limitations, primarily that sample sizes were relatively small. The correspondingly reduced statistical power may prevent the detection of small effect sizes, and as such results must be interpreted with this in mind. This minimal sample size also prevents conclusions from being anything more than preliminary and speculative. To ensure that conclusions are supported, additional data is required. Subsequent replication and expansion of the work would illustrate more fully the relationship between learning outcomes and the expression of the genes of interest. The present data does suggest that subsequent work is likely to yield continuing interesting results.

Likewise, it is worth noting that sample RNA concentrations for the genes of interest were low. For most genes of interest, cycle threshold values were consistently above 30 , indicating very low concentrations and binding efficiency with cDNA primers. This is likely due to the extraction method used, which was designed for the extraction of both RNA and DNA products, as well as the overall small size of the RNA fragments of interest. MicroRNA fragments, in particular, are generally only around 20 nucleotides in length [64]. As such, the high cycle thresholds must be interpreted with caution, but are likely still indicative of appropriate expression.

\section{ACKNOWLEDGEMENTS}

The authors would like to thank Dr. Ana Chicas-Mosier, Jack Lafferrandre, and Sahar Delkash for their assistance in data collection and curation.

\section{AUTHOR CONTRIBUTIONS}

Conceptualization, M.R. and T.B.; methodology, M.R. and T.B.; validation, A.S., M.R. and T.B.; formal analysis, T.B.; investigation, M.R. and T. B.; resources, C.A. and M.R.; data curation, T.B.; writing-original draft preparation, M.R. and T.B.; writing—review and editing, A.S., C.A., and T.B.; visualization, T.B.; supervision, C.A.; project administration, C.A., and M.R.; funding acquisition, C.A., and M.R. All authors have read and agreed to the published version of the manuscript.

\section{FUNDING}

Dr. Radi was supported in part by a grant from the Egyptian Ministry of Higher Education and Scientific Research - Cultural Affairs and Missions. Funding was also provided by NSF-REU (2016-1560389), (1950805) and NSF-PIRE (1743753) grants.

\section{CONFLICTS OF INTEREST}

The authors declare no conflict of interest. 


\section{REFERENCES}

1. Honeybee Genome Sequencing Consortium (2006) Insights into Social Insects from the Genome of the Honeybee Apis mellifera. Nature, 443, 931. https://doi.org/10.1038/nature05400

2. Ilyasov, R.A. (2016) Features of the Honey Bee Apis mellifera Genome versus Fruit Fly Drosophila melanogaster. Journal of Investigative Genomics, 3, 19-21. https://doi.org/10.15406/jig.2016.03.00044

3. Menzel, R. and Erber, J. (1978) Learning and Memory in Bees. Scientific American, 239, 102-111. https://doi.org/10.1038/scientificamerican0778-102

4. Abramson, C.I., Stone, S.M., Ortez, R.A., Luccardi, A., Vann, K.L., Hanig, K.D. and Rice, J. (2000) The Development of an Ethanol Model Using Social Insects I: Behavior Studies of the Honey Bee (Apis mellifera L.). Alcoholism: Clinical and Experimental Research, 24, 1153-1166.

https://doi.org/10.1111/j.1530-0277.2000.tb02078.x

5. Abramson, C.I., Sanderson, C., Painter, J., Barnett, S. and Wells, H. (2005) Development of an Ethanol Model Using Social Insects: V. Honeybee Foraging Decisions under the Influence of Alcohol. Alcohol, 36, 187-193. https://doi.org/10.1016/j.alcohol.2005.09.001

6. Menzel, R., Erber, J. and Masuhr, T. (1974) Learning and Memory in the Honeybee. In: Barton, B.L., Ed., Experimental Analysis of Insect Behaviour, Springer, Berlin. https://doi.org/10.1007/978-3-642-86666-1 14

7. Menzel, R. (1993) Associative Learning in Honey Bees. Apidologie, 24, 157-168. https://doi.org/10.1051/apido:19930301

8. Walldorf, U., Fleig, R. and Gehring, W.J. (1989) Comparison of Homeo Box-Containing Genes in the Honeybee and Drosophila. Proceedings of the National Academy of Sciences of the United States of America, 86, 99719975. https://doi.org/10.1073/pnas.86.24.9971

9. Kohno, H. and Kubo, T. (2019) Genetics in the Honey Bee: Achievements and Prospects toward the Functional Analysis of Molecular and Neural Mechanisms Underlying Social Behaviors. Insects, 10, 348.

https://doi.org/10.3390/insects10100348

10. Black, T.E., Fofah, O., Dinges, C.W., Ortiz-Alvarado, C.A., Avalos, A., Ortiz-Alvarado, Y. and Abramson, C.I. (2020) Effects of Aversive Conditioning on Expression of Physiological Stress in Honey Bees (Apis mellifera). Neurobiology of Learning and Memory, 178, Article ID: 107363. https://doi.org/10.1016/j.nlm.2020.107363

11. Bitterman, M.E., Menzel, R., Fietz, A. and Schäfer, S. (1983) Classical Conditioning of Proboscis Extension in Honeybees (Apis mellifera). Journal of Comparative Psychology, 97, 107.

https://doi.org/10.1037/0735-7036.97.2.107

12. Abramson, C.I., Mixson, T.A., Çakmak, I., Place, A.J. and Wells, H. (2008) Pavlovian Conditioning of the Proboscis Extension Reflex in Harnessed Foragers Using Paired vs. Unpaired and Discrimination Learning Paradigms: Tests for Differences among Honeybee Subspecies in Turkey. Apidologie, 39, 428-435. https://doi.org/10.1051/apido:2008025

13. Giannoni-Guzmán, M.A., Giray, T., Agosto-Rivera, J.L., Stevison, B.K., Freeman, B., Ricci, P., Abramson, C.I., et al. (2014) Ethanol-Induced Effects on Sting Extension Response and Punishment Learning in the Western Honey Bee (Apis mellifera). PLoS ONE, 9, e100894. https://doi.org/10.1371/journal.pone.0100894

14. Amaya-Márquez, M., Hill, P.S., Abramson, C.I. and Wells, H. (2014) Honey Bee Location- and Time-Linked Memory Use in Novel Foraging Situations: Floral Color Dependency. Insects, 5, 243-269. https://doi.org/10.3390/insects5010243

15. Hill, P.S., Wells, P.H. and Wells, H. (1997) Spontaneous Flower Constancy and Learning in Honey Bees as a Function of Colour. Animal Behaviour, 54, 615-627. https://doi.org/10.1006/anbe.1996.0467

16. Menzel, R. (1999) Memory Dynamics in the Honeybee. Journal of Comparative Physiology A, 185, 323-340. 


\section{https://doi.org/10.1007/s003590050392}

17. Dinges, C.W., Avalos, A., Abramson, C.I., Craig, D.P.A., Austin, Z.M., Varnon, C.A., Dal, F.M., Giray, T. and Wells, H. (2013) Aversive Conditioning in Honey Bees (Apis mellifera anatolica): A Comparison of Drones and Workers. The Journal of Experimental Biology, 216, 4124-4134. https://doi.org/10.1242/jeb.090100

18. Black, T.E., Fofah, O., Giray, T., Wells, H., Le Conte, Y. and Abramson, C.I. (2018) Influence of Environmental Experience on Aversive Conditioning in Honey Bees (Apis mellifera L.). Apidologie, 49, 647-659. https://doi.org/10.1007/s13592-018-0592-0

19. Nouvian, M. and Galizia, C.G. (2019) Aversive Training of Honey Bees in an Automated Y-Maze. Frontiers in Physiology, 10, 678. https://doi.org/10.3389/fphys.2019.00678

20. Gross, H.J., Pahl, M., Si, A., Zhu, H., Tautz, J. and Zhang, S. (2009) Number-Based Visual Generalisation in the Honeybee. PLoS ONE, 4, e4263. https://doi.org/10.1371/journal.pone.0004263

21. Wainselboim, A.J., Roces, F. and Farina, W.M. (2002) Honeybees Assess Changes in Nectar Flow within a Single Foraging Bout. Animal Behaviour, 63, 1-6. https://doi.org/10.1006/anbe.2001.1879

22. Hammer, M. and Menzel, R. (1995) Learning and Memory in the Honeybee. Journal of Neuroscience, 15, 16171630. https://doi.org/10.1523/JNEUROSCI.15-03-01617.1995

23. Abramson, C.I., Place, A.J., Aquino, I.S. and Fernandez, A. (2004) Development of an Ethanol Model Using Social Insects: IV. Influence of Ethanol on the Aggression of Africanized Honey Bees (Apis mellifera L.). Psychological Reports, 94, 1107-1115. https://doi.org/10.2466/pr0.94.3c.1107-1115

24. Hranitz, J.M., Abramson, C.I. and Carter, R.P. (2010) Ethanol Increases HSP70 Concentrations in Honeybee (Apis mellifera L.) Brain Tissue. Alcohol, 44, 275-282. https://doi.org/10.1016/j.alcohol.2010.02.003

25. Evan, N., Devaud, J.M. and Barron, A. (2012) General Stress Responses in the Honey Bee. Insects, 3, 1271-1298. https://doi.org/10.3390/insects3041271

26. Hunt, G.J., Page, R.E., Fondrk, M.K. and Dullum, C.J. (1995) Major Quantitative Trait Loci Affecting Honey Bee Foraging Behavior. Genetics, 141, 1537-1545. https://doi.org/10.1093/genetics/141.4.1537

27. Schafer, D.A. and Schroer, T.A. (1999) Actin-Related Proteins. Annual Review of Cell and Developmental Biology, 15, 341-363. https://doi.org/10.1146/annurev.cellbio.15.1.341

28. Pollard, T.D. (2016) Actin and Actin-Binding Proteins. Cold Spring Harbor Perspectives in Biology, 8, a018226. https://doi.org/10.1101/cshperspect.a018226

29. Mullins, R.D. and Pollard, T.D. (1999) Structure and Function of the Arp2/3 Complex. Current Opinion in Structural Biology, 9, 244-249. https://doi.org/10.1016/S0959-440X(99)80034-7

30. Mullins, R. (2013) Actin-Related Proteins. In: Lennarz, W.J. and Lane, M.D., Eds., Encyclopedia of Biological Chemistry, Elsevier, Amsterdam, 36-41. https://doi.org/10.1016/B978-0-12-378630-2.00468-0

31. Li, J., Feng, M., Zhang, Z. and Pan, Y. (2008) Identification of the Proteome Complement of Hypopharyngeal Glands from Two Strains of Honeybees (Apis mellifera). Apidologie, 39, 199-214. https://doi.org/10.1051/apido:2007059

32. Poch, O. and Winsor, B. (1997) Who's Who among the Saccharomyces cerevisiae Actin-Related Proteins? A Classification and Nomenclature Proposal for a Large Family. Yeast, 13, 1053-1058. https://doi.org/10.1002/(SICI)1097-0061(19970915)13:11<1053::AID-YEA164>3.0.CO;2-4

33. Cristino, A.S., Barchuk, A.R., Freitas, F.C., Narayanan, R.K., Biergans, S.D., Zhao, Z., Claudianos, C., et al. (2014) Neuroligin-Associated microRNA-932 Targets Actin and Regulates Memory in the Honeybee. Nature Communications, 5, Article No. 5529. https://doi.org/10.1038/ncomms6529

34. Lamprecht, R. (2016) The Role of Actin Cytoskeleton in Memory Formation in Amygdala. Frontiers in Molecular Neuroscience, 9, 23. https://doi.org/10.3389/fnmol.2016.00023 
35. Silva, A.J., Paylor, R., Wehner, J.M. and Tonegawa, S. (1992) Impaired Spatial Learning in Alpha-CalciumCalmodulin Kinase II Mutant Mice. Science, 257, 206-211. https://doi.org/10.1126/science.1321493

36. Abeliovich, A., Paylor, R., Chen, C., Kim, J.J., Wehner, J.M. and Tonegawa, S. (1993) PKC $\gamma$ Mutant Mice Exhibit Mild Deficits in Spatial and Contextual Learning. Cell, 75, 1263-1271. https://doi.org/10.1016/0092-8674(93)90614-V

37. Tejedor, F., Zhu, X.R., Kaltenbach, E., Ackermann, A., Baumann, A., Canal, I., Pongs, O., et al. (1995) Minibrain: A New Protein Kinase Family Involved in Postembryonic Neurogenesis in Drosophila. Neuron, 14, 287-301. https://doi.org/10.1016/0896-6273(95)90286-4

38. Giese, K.P. and Mizuno, K. (2013) The Roles of Protein Kinases in Learning and Memory. Learning \& Memory, 20, 540-552. https://doi.org/10.1101/lm.028449.112

39. Nara, K., Akasako, Y., Matsuda, Y., Fukazawa, Y., Iwashita, S., Kataoka, M. and Nagai, Y. (2001) Cloning and Characterization of a Novel Serine/Threonine Protein Kinase Gene Expressed Predominantly in Developing Brain. European Journal of Biochemistry, 268, 2642-2651. https://doi.org/10.1046/j.1432-1327.2001.02157.x

40. Stork, O., Zhdanov, A., Kudersky, A., Yoshikawa, T., Obata, K. and Pape, H.C. (2004) Neuronal Functions of the Novel Serine/Threonine Kinase Ndr2. Journal of Biological Chemistry, 279, 45773-45781.

https://doi.org/10.1074/jbc.M403552200

41. Lee, P.T., Lin, G., Lin, W.W., Diao, F., White, B.H. and Bellen, H.J. (2018) A Kinase-Dependent Feed forward Loop Affects CREBB Stability and Long Term Memory Formation. Elife, 7, e33007.

https://doi.org/10.7554/eLife.33007.022

42. Ghildiyal, M. and Zamore, P.D. (2009) Small Silencing RNAs: An Expanding Universe. Nature Reviews Genetics, 10, 94-108. https://doi.org/10.1038/nrg2504

43. Ashraf, S.I., McLoon, A.L., Sclarsic, S.M. and Kunes, S. (2006) Synaptic Protein Synthesis Associated with Memory Is Regulated by the RISC Pathway in Drosophila. Cell, 124, 191-205.

https://doi.org/10.1016/j.cell.2005.12.017

44. Schratt, G. (2009) microRNAs at the Synapse. Nature Reviews Neuroscience, 10, 842-849.

https://doi.org/10.1038/nrn2763

45. Edbauer, D., Neilson, J.R., Foster, K.A., Wang, C.F., Seeburg, D.P., Batterton, M.N., Sheng, M., et al. (2010) Regulation of Synaptic Structure and Function by FMRP-Associated microRNAs miR-125b and miR-132. Neuron, 65, 373-384. https://doi.org/10.1016/j.neuron.2010.01.005

46. Gao, J., Wang, W.Y., Mao, Y.W., Gräff, J., Guan, J.S., Pan, L., Tsai, L.H., et al. (2010) A Novel Pathway Regulates Memory and Plasticity via SIRT1 and miR-134. Nature, 466, 1105-1109. https://doi.org/10.1038/nature09271

47. Behura, S.K. and Whitfield, C.W. (2010) Correlated Expression Patterns of microRNA Genes with Age-Dependent Behavioural Changes in Honeybee. Insect Molecular Biology, 19, 431-439.

https://doi.org/10.1111/j.1365-2583.2010.01010.x

48. Greenberg, J.K., Xia, J., Zhou, X., Thatcher, S.R., Gu, X., Ament, S.A. and Ben-Shahar, Y. (2012) Behavioral Plasticity in Honey Bees Is Associated with Differences in Brain microRNA Transcriptome. Genes, Brain and Behavior, 11, 660-670. https://doi.org/10.1111/j.1601-183X.2012.00782.x

49. Liu, F., Peng, W., Li, Z., Li, W., Li, L., Pan, J., Su, S., et al. (2012) Next-Generation Small RNA Sequencing for microRNAs Profiling in Apis mellifera: Comparison between Nurses and Foragers. Journal of Insect Behavior, 21, 297-303. https://doi.org/10.1111/j.1365-2583.2012.01135.x

50. Shi, Y.Y., Wu, X.B., Huang, Z.Y., Wang, Z.L., Yan, W.Y. and Zeng, Z.J. (2012) Epigenetic Modification of Gene Expression in Honey Bees by Heterospecific Gland Secretions. PLoS ONE, 7, e43727.

https://doi.org/10.1371/journal.pone.0043727 
51. Weaver, D.B., Anzola, J.M., Evans, J.D., Reid, J.G., Reese, J.T., Childs, K.L., Elsik, C.G., et al. (2007) Computational and Transcriptional Evidence for microRNAs in the Honey Bee Genome. Genome Biology, 8, 1-12. https://doi.org/10.1186/gb-2007-8-6-r97

52. Collins, D.H., Mohorianu, I., Beckers, M., Moulton, V., Dalmay, T. and Bourke, A.F. (2017) MicroRNAs Associated with Caste Determination and Differentiation in a Primitively Eusocial Insect. Scientific Reports, 7, Article No. 45674. https://doi.org/10.1038/srep45674

53. Ren, Z., Yu, J., Wu, Z., Si, W., Li, X., Liu, Y., Chen, D., et al. (2018) MicroRNA-210-5p Contributes to Cognitive Impairment in Early Vascular Dementia Rat Model through Targeting Snap25. Frontiers in Molecular Neuroscience, 11, 388. https://doi.org/10.3389/fnmol.2018.00388

54. Biswas, S., Russell, R.J., Jackson, C.J., Vidovic, M., Ganeshina, O., Oakeshott, J.G. and Claudianos, C. (2008) Bridging the Synaptic Gap: Neuroligins and Neurexin I in Apis mellifera. PLoS ONE, 3, e3542. https://doi.org/10.1371/journal.pone.0003542

55. Qian, J., Tu, R., Yuan, L. and Xie, W. (2016) Intronic miR-932 Targets the Coding Region of Its Host Gene, Drosophila neuroligin2. Experimental Cell Research, 344, 183-193. https://doi.org/10.1016/j.yexcr.2016.01.017

56. Lin, Q., Wei, W., Coelho, C.M., Li, X., Baker-Andresen, D., Dudley, K., Bredy, T.W., et al. (2011) The BrainSpecific microRNA miR-128b Regulates the Formation of Fear-Extinction Memory. Nature Neuroscience, 14, 1115. https://doi.org/10.1038/nn.2891

57. Fink, C.C., Bayer, K.U., Myers, J.W., Ferrell Jr., J.E., Schulman, H. and Meyer, T. (2003) Selective Regulation of Neurite Extension and Synapse Formation by the $\beta$ But Not the $\alpha$ Isoform of CaMKII. Neuron, 39, 283-297. https://doi.org/10.1016/S0896-6273(03)00428-8

58. Seeley, T.D. (1995) The Wisdom of the Hive: The Social Physiology of Honey Bee Colonies. Harvard University Press, Cambridge.

59. Simonnet, M.M., Berthelot-Grosjean, M. and Grosjean, Y. (2014) Testing Drosophila Olfaction with a Y-Maze Assay. Journal of Visualized Experiments, 88, e51241. https://doi.org/10.3791/51241

60. Smith, B.H., Abramson, C.I. and Tobin, T.R. (1991) Conditional Withholding of Proboscis Extension in Honeybees (Apis mellifera) during Discriminative Punishment. Journal of Comparative Psychology, 105, 345. https://doi.org/10.1037/0735-7036.105.4.345

61. Abramson, C.I. and Boyd, B.J. (2001) An Automated Apparatus for Conditioning Proboscis Extension in Honey Bees, Apis mellifera L. Journal of Entomological Science, 36, 78-92. https://doi.org/10.18474/0749-8004-36.1.78

62. Hitesh, V.D. and Abramson, C.I. (2020) The Use of 3D Printing in Comparative Research and Teaching. International Journal of Comparative Psychology, 33, 1-8. https://doi.org/10.46867/ijcp.2020.33.05.12

63. Wells, H., Wells, P.H. and Smith, D.M. (1981) Honeybee Responses to Reward Size and Colour in an Artificial Flower Patch. Journal of Apicultural Research, 20, 172-179. https://doi.org/10.1080/00218839.1981.11100493

64. Macedo, L.M.F., Nunes, F.M.F., Freitas, F.C.D.P., Pires, C.V., Tanaka, E.D., Martins, J.R., Simões, Z.L.P., et al. (2016) MicroRNA Signatures Characterizing Caste-Independent Ovarian Activity in Queen and Worker Honeybees (Apis mellifera L.). Insect Molecular Biology, 25, 216-226. https://doi.org/10.1111/imb.12214 